\title{
Juvenile production of Amphiprion bicinctus (Pomacentridae, Teleostei) and rehabilitation of impoverished habitats
}

\author{
Ahron Maroz, Lev Fishelson* \\ Underwater Observatory and Aquarium, Eilat, Israel and Department of Zoology, Tel Aviv University, Tel-Aviv 69978, Israel
}

\begin{abstract}
This study on the Red Sea fish Amphiprion bicinctus was aimed at developing a method of producing large numbers of juveniles for reintroduction into their symbiotic sea anemones in natural habitats. By establishing reproductive pairs in captivity and providing them with a diet of rotifers and various stages of nauplius and adult Artemia salina, reproduction was achieved at frequencies of 2 to 3 times per month per pair, resulting in large numbers of larvae. Juveniles attaining 16 to $28 \mathrm{~mm}$ TL were introduced into sea anenomes on the coral reefs at Eilat Israel, at depths of 10 to $25 \mathrm{~m}$. Despite heavy losses, numerous juveniles successfully acclimated and survived in their new habitat, many in anenomes previously occupied by adult fish. Three years of follow-up revealed that 8 pairs of such reintroduced fush had grown into maturity and become reproductive. It would appear that this method of production in captivity followed by resettlement in impoverished natural habitats may be effective for community rehabilitation.
\end{abstract}

KEY WORDS: Amphiprion Propagation Reintroduction in nature

During the past few decades coral reef fish populations have been intensively investigated, using Scuba and other methods of underwater observation (Fishelson et al. 1974, Ehrlich 1975). Among the most interesting fishes are those of the genus Amphiprion (BrusleSicard \& Reinboth 1990, Brusle-Sicard et al. 1994), which live symbiotically with sea anemones Gyrostoma, Radianthus and other closely related genera (Fishelson 1965 , Fricke 1980). A. bicinctus is the only species of this genus to occur in the Red Sea. It is a protandrous, monogamous species which forms permanent pairs in host anemones and can be found in the shallow subtidal to a depth of approximately $10 \mathrm{~m}$. In the Gulf of Aqaba these symbiotic associations are encountered below the rocky tide line, in the channel formed by the

\footnotetext{
•E-mail: fishelv@ccsg.tau.ac.ll
}

fringing reef, and along the forereef wall. Although several papers have been published on the sociobiology of these fish (see Allen 1972), several phenomena concerning pair bonding, propagation, postlarval settlement and survival have not yet been investigated.

During the last 2 decades the coral reef habitats worldwide and at Eilat, Israel, have been strongly subjected to anthropogenic stressors (Fishelson 1977, 1995), resulting in degraded coral cover and impoverished fish communities (Fishelson 1995). Shallow-water subtidal organisms, including sea anemones and their fish symbionts, have been particularly badly affected. The most severely damaged organisms were the digging sea anemones Radianthus koseirensis, which are the primary targets for settlement of postmetamorphic amphiprions. Although protected by the Israeli Nature Protection Law of 1963, the amphiprion population has dramatically declined and during recent years an increasing number of sea anemones are being seen without their symbiotic fish.

The current study had 2 main goals: (1) to extend knowledge on reproduction and larval formation of amphiprions in nature and captivity; and (2) to resettle juveniles in the sea and monitor survival and growth of newly settled fish in nature. The ultimate aim was to develop a methodology that would enable rehabilitation of the declining population of sea anemone fish in the Eilat region.

Methods. Production of juveniles: Experiments on the propagation of Amphiprion bicinctus and observations on their behavior were conducted in aquaria at the Underwater Observatory, Coral Reserve, Eilat, where many years of experience have been gained in breeding these fish in the presence of sea anemones. Based on the collected data, a program of intense breeding was initiated to produce enough fish for reintroduction into their natural habitats with the sea anemones. The fish were kept in PVC aquaria $(60 \times 40 \times 50 \mathrm{~cm})$ with rounded 
corners and a glass front. The water was maintained at 25 to $26^{\circ} \mathrm{C}$, strongly aerated, constantly filtered and. illuminated by quartz spotlights and Gro-Lux fluorescent tubes under a 12L:12D lighting regime. In each container was 1 large sea anemone, usually attached to a flat rock, and 1 pair of $A$. bicinctus: a smaller male and a dominant female. These monogamic pairs were created by taking fish of 45 to $60 \mathrm{~mm}$ TL from the communal tanks and placing them in pairs in separate aquaria. The tolerance of a larger fish for a smaller one was always better than the tolerance between 2 fish of equal size, which usually demonstrated high aggression. A pair of fish which showed mutual attachment by remaining close or swimming in unison could on the same or following day be transferred into a container for spawning. We obtained 12 pairs in this way for larval production. These adult fish were fed daily with live Artemia salina. The resulting spawn was attached by the female to a clean part of the rock, close to the sea anemone's body. Hatching occurred 9 to $10 \mathrm{~d}$ following spawning. Because of the pinkish color of the yolk, the larvae were easily recognizable and collected for transfer to separate aquaria. These aquaria were funnel-shaped, $50 \mathrm{~cm}$ upper diameter and $1 \mathrm{~m}$ high, with constant water circulation. Larvae aged 3 to $4 \mathrm{~d}(5.5$ to $6.0 \mathrm{~mm}$ total length, TL) began feeding, and were initially provided with rotifers $\left(330 \mu \mathrm{m}, 10000 \mathrm{I}^{-1}\right.$ water $)$. The rotifer culture was kept in a $5 \mathrm{~m}^{3}$ container, in a mixture of one-third fresh-and two-third sea-water, at $28^{\circ} \mathrm{C}$, enriched with vitamins. The rotifers were fed with the unicellular algae Tetrasalmus and Nannochlorocystis at a concentration of $50000 \mathrm{l}^{-1}$ water. The algae were grown in $2 \mathrm{~m}^{3}$ containers, $\mathrm{pH} 8.5$, strongly aerated and illuminated with $150 \mathrm{~W} 0.5 \mathrm{~m}^{-3}$ water. The purity of these cultures was controlled by UV-light and ozonizers.

Juveniles aged $5 \mathrm{~d}(7.0$ to $8.0 \mathrm{~mm}$ TL) were ready to feed upon freshly hatched Artemia nauplii and were fed daily with 1000 nauplii $\mathrm{l}^{-1}$ water. From Day 16 the larvae were fed nauplii only and from Day 20 they were also supplied with larger stages of Artemia. Daily Consumption was 50 to 300 nauplii, depending on the size of the fish. At the beginning of growth the density of larvae was 15 to $20 \mathrm{l}^{-1}$ water, but as soon as they began to demonstrate aggression, their density was reduced and water circulation was increased. In addition to spawn from captivity spawn was also taken from the sea together with the piece of the rock to which it was attached. All spawn could also be hatched without parental fish, using strong aeration to agitate the eggs intensively.

The resulting juveniles ( 16 to $20 \mathrm{~mm}$ TL) were transported to the sea in small, closed containers and directly released between tentacles of host anemones previously marked for observations. In most instances, such juveniles immediately dived into the host, be- having in a manner previously described by Fishelson (1965)

The sites for rehabilitation studies were selected from a number of localities close to the Underwater Observatory, where symbiotic sea anemones with or without amphiprions had been found, at depths of 4 to $12 \mathrm{~m}$. The sea anemones were Gyrostoma quadricolor, Radianthus koseirensis and Radianthus ritteri. A total of 26 host anemones in the sea and 12 in captivity were observed.

Resettling of juvenile fish: The rehabilitation experiments were carried out from May 1993 to June 1995. During this time 3 types of experiments were performed: (1) juvenile fish were introduced into unoccupied host anenomes; (2) juveniles were placed among hosts already containing 1 or 2 adult fish; (3) young adults of 40 to $60 \mathrm{~mm}$ TL were added to a single or a pair of resident fish in their host anemone. In this part of the study we used a total of about 300 fish of 16 to $20 \mathrm{~mm}$ TL and 20 fish of 40 to $60 \mathrm{~mm}$ TL. Each of the experimental sea anemones was visited every 1 or $2 \mathrm{wk}$, or once a month, according to the type of observation.

Results. Pair formation and spawning: The behavioral repertoire leading to formation of a permanent pair in Amphiprion bicinctus starts as agonistic (antagonistic) encounters in juvenile fish of 20 to $25 \mathrm{~mm}$ TL, becoming stronger and more frequent in the 45 to $50 \mathrm{~mm}$ TL fish. Adult fish start pairing by chasing and attempting to bite before slowly changing to more peaceful displays; the fish remain close together and follow each other around. Within a few hours the bond usually becomes established, especially if the fish are of different sizes. We were thus also able to produce new pairs in nature by introducing a smaller adult amphiprion to sea anemones hosting only 1 resident fish. Once a pair is formed, they remain together for 1 to $2 \mathrm{yr}$, beginning to spawn at 60 to $70 \mathrm{~mm}$ body length in males and 85 to $90 \mathrm{~mm}$ in females. In 6 instances of the 22 pairs observed, we could see that despite well-established bonds with time the female started to behave antagonistically towards the male as soon as he reached her size. Such females are very receptive to new, smaller amphiprions, and it is possible that the masculinity of the larger protandric male concomitantly decreases toward a sex-change. This is also the most suitable time for smaller fish, living on the periphery of the host, to be accepted.

As mentioned previously and also described in several papers, the spawn of Amphiprion bicinctus, as in all. amphiprions, is adhesive due to sticky filaments on one of the poles of its egg chorions. A spawn occupies a 60 to $80 \mathrm{~cm}^{2}$ area and contains 800 to 1000 eggs. The experimental pairs spawned from May to October, each producing 8 to 10 batches of eggs, an approximate total of 7000 to 10000 eggs. Hatching and swim- 
Table 1. Amphiprion bicinctus. Survival of juveniles introduced into symbiotic sea anomones at Eilat, Israel

\begin{tabular}{|c|c|c|c|c|c|c|c|}
\hline & \multirow{2}{*}{$\begin{array}{l}\text { No. of } \\
\text { anemones }\end{array}$} & \multirow{2}{*}{$\begin{array}{l}\text { No. of untro- } \\
\text { duced juveniles }\end{array}$} & \multicolumn{4}{|c|}{ No. of survivors } & \multirow{2}{*}{$\begin{array}{c}\text { No. of spawns } \\
\text { (pairs) }\end{array}$} \\
\hline & & & $3 \mathrm{mo}$ & $6 \mathrm{mo}$ & 9 mo & $12 \mathrm{mo}$ & \\
\hline Gyrostoma quadricolor & 18 & 160 & 70 & 50 & 25 & 20 & 8 \\
\hline Radianthus ritten & 6 & 80 & 40 & 20 & 16 & 12 & 4 \\
\hline Radianthus koseirensis & 14 & 80 & 60 & 40 & $4^{\mathrm{c}}$ & $2^{\mathrm{b}}$ & - \\
\hline
\end{tabular}

ming up of juveniles occurs on Days 9 and 10 , usually in the late afternoon, and the fish settle 10 to 12 d later Because in undisturbed habitats the number of amphiprions counted under natural conditions remains more or less constant, as has also been observed in other stationary fish (Shpigel \& Fishelson 1986), it is obvious that the majority of such juveniles are destroyed, possibly by predation. It is thus desirable, under certain conditions, to collect spawn from the sea, grow the juveniles in captivity and then release them into the sea anemones when they are larger and less prone to predation. In most instances, when spawn is taken from breeding pairs they will produce a new batch of eggs within 7 to $9 \mathrm{~d}$, a phenomenon wellknown from passerine birds.

Reestablishment of new amphiprions in nature: Attempts to repopulate sea anemones with Amphiprion bicinctus were made on Gyrostoma quadricolor, Radianthus ritteri and $R$. koseirensis. Juveniles of 16 to $25 \mathrm{~mm} \mathrm{TL}$, in pairs or small groups of 6 to 10, were released into selected host anemones and monitored. In $25 \%$ of the introductions the recruits disappeared within a few days or weeks. In such instances new juveniles were introduced. In $35 \%$ of cases the introduced fish remained in their hosts for several months, while $40 \%$ of the fish became firmly established and could be followed for longer periods. Table 1 summarizes the results of introduction on the 3 sea anemones studied.

In some instances it was necessary to repeat such introductions 3 or 4 times until positive results were achieved. The growth of new recruits slowly increased by 0.5 to $2.0 \mathrm{~mm}$ monthly. In all instances where individual juvenile fish were added to single larger amphiprions in their host, they remained there and grew to 45 to $50 \mathrm{~mm}$ TL, forming a pair with the original occupant. In all 20 experiments the added fish was a male. In 7 Gyrostona quadricolor and 2 Radianthus ritteri, the introduced fish formed a reproductive pair with the older one, attaining 80 to $110 \mathrm{~mm}$ TL after 6 to $12 \mathrm{mo}$ of growth, and successfully producing a first spawn. In 2 additional $G$. quadicolor, we followed the growth of 2 groups of juveniles of 12 and $16 \mathrm{~mm}$, respectively, which were introduced in September 1993: by February 1994. they had attained 21 and $25 \mathrm{~mm}$, respectively; by May 1994, 27 and $35 \mathrm{~mm}$, respectively; by November 1994, 36 and $44 \mathrm{~mm}$, respectively; and finally, in June 1995, when they spawned for the first time, they had reached around $91 \mathrm{~mm}$ (males) and $112 \mathrm{~mm}$ (females). The introductions into $R$. koseirensis were less successful, for 2 reasons: (1) these sea anemones tend to retract into the soft bottom, often leaving their fish symbionts exposed; and (2) as observed in the sea (Fishelson 1965), amphiprions of 35 to $40 \mathrm{~mm}$ TL usually change hosts, from the sanddwelling $R$. koseirensis to Gyrostoma spp. In this study, too, the occurrence of such sub-adult amphiprions on the marked $G$. quadricolor was noted it is possible that they had transferred from $R$. koseirensis. It would appear that the method we employed for reintroduction of amphiprion fishes into a habitat with a declining population of this species can also serve as a model for the reestablishment of other fish on stressed coral reefs. For any such species, however, the requisite habitat and biological demands should first be studied, and the appropriate progeny production technique established.

\section{LITERATURE CITED}

Allen GR (1972) The anemone fishes. Their classification and biology. TFH Publications, Neptune, NJ

Brusle-Sicard S, Reinboth R (1990) Protandnc hermaphrodite peculiarities in Amphipron franatus Brevoort (Teleostel, Pomacentridae). J Fish Biol 36:383-390

Brusle-Sicard S, Reinboth R, Fourcault B (1994) Germinal potentialities during sexual changes in a protandric hermaphrodite, Amphiprion frenatus (Telesotel, Pomacentridae). J Fish Biol 45:597-611

Ehrlich PR (1975) The population biology of coral reef fishes. Annu Rev Ecol Syst 6:211-247

Fishelson L (1965) Observations and experiments on the Red Sea Anemones and their symbiotic fish Amphiprion bicinctus. Sea Fish Res Stn Haifa Bull 39:1-14

Fishelson L (1977) Sociobiology of feeding behavior of coral reef fish along the coral reef of the Gulf of Eilat, Red Sea. Israel J Zool 26:114-134

Fishelson L (1995) Elat (Gulf of Aqaba) littoral; life on the red line of biodegradation. Israel J Zool 41:43-55

Fishelson L, Popper D, Avigdor A (1974) Biosociology and ecology of Pomacentrid fishes around the Sinai Peninsula (northern Red Sea). J Fish Biol 6:110-133

Fricke HW (1980) Control of different mating systems in a coral reef fish by one environment factor. Anim Behav 28:561-569

Shpigel M. Fishelson L (1986) Behaviour and physiology of coexistence in two species of Dascyllus (Pomacentridae, Teleostel). Environ Biol Fish 17:253-265 